The Egyptian International Journal of Engineering Sciences \& Technology, Vol 5, No 1 (2001)

\title{
Off-Road Tyres Tractive Performance Prediction under Different Ru Coiwitions
}

M Watny

\begin{abstract}
The rolling resistance and maximum tractive force for off-road tyres were used to evaluate the tractive performance under different running conditions. Two tyres have been used each was operated at four different inflation pressures and different load in sand. The results were compared with the well-established empirical techniques developed to predict tyre tractive performance. A single wheel tester has been used to measure the tractive performance for off-road tyres. The result indicate that, lowering tyre inflation pressures increases tractive force and rolling resistance, and the increase of applied load increases the rolling resistance and at a certain inflation pressure where any increase of load causes a reduction of traction force. On soft soil surface, the smaller tyre had the lower performance than the larger one.
\end{abstract}

